\title{
Lesões das vias aéreas superiores após intubação endotraqueal em eqüinos
}

\section{Upper Airways Lesions After endotracheal intubation in equines}

Rodrigo Ramos de FREITAS'; Angelo João STOPIGLIA'; Luis Claudio Lopes Correia da SILVA'; Denise Tabacchi FANTON'.
CORRESPONDENCE TO

Angelo Jaăo Stopiglia

Departamento de Cirungia

Faculdade de Modicina Velerinaria a

Zootecnis da USP

Av. Prof. Dr. Ortando Marques de

Paiva, 87 - Cidade Universitaria

Amando Salles de Oliveira

05508-900 - São Paulo - SP - Brasil

e-mait: stopa Qusp.br

1 - Departamento de Cirurgia

Faculdade de Medicina

Veterinária e Zootecnia da

$U S P$ - SP

\section{RESUMO}

A intubação endotraqueal nos eqüinos atualmente é rotina nas salas cirúrgicas das grandes Faculdades, Jockeys Clubes, Hípicas, etc... É um procedimento invasivo, portanto, não deixa de apresentar riscos; porém suas vantagens excedem em muito suas desvantagens. O objetivo desse experimento foi procurar indícios de que a sonda endotraqueal possa causar lesōes nas vias aéreas superiores dos eqüinos quando submetidos a intubação endotraqueal e quais suas possiveis conseqüências.

Os resultados foram avaliados segundo tempo de execução do ato operatório, idade dos eqüinos, raça dos animais, peso, sexo, número de vezes que foram necessárias para realizar a intubação orotraqueal, diâmetro da sonda endotraqueal e pressão utilizada no "CUFF". No tocante às lesões em si, avaliamos o tipo e o grau, a saber: sem lesāo; lesōes leves onde entendemos equimoses que foram classificadas conforme intensidade da lesão em,+++ ou +++ ; lesōes moderadas onde entendemos hematomas, que conforme o grau foram de,,++++++ ; lesões como escoriações, que se classificam em leves, moderadas e graves e que, conforme o grau da lesão, correspondem respectivamente $\mathrm{a}+$, leve +++ , moderada e +++, grave; e perfurações. Quanto aos resultados obtidos, não foram observadas diferenças que pudessem correlacionar aparecimento de lesão e os parâmetros analisados segundo metodologia aplicada. Pelos resultados obtidos com a metodologia empregada, concluiu-se que as intubações endotraqueais em eqüinos provocaram lesões nas vias aéreas superiores, entre as quais constatamos: equimose, ulceração, hematomas e escoriação; o local lesado observado com maior freqüência foi a região da traquéia onde se posiciona o "cuff"; a lesão encontrada com maior freqüência foi a equimose.

\section{UNITERMOS: Intubação Endotraqueal, Lesões, Eqüinos, Pressão Cuff}

\section{INTRODUÇÃO}

A realização de intubação endotraqueal nos eqüinos após a indução anestésica e manutenção desta, vem-se tornando rotina cada vez utilizada mais amiúde em nosso meio, mormente nas últimas duas décadas, nos centros cinúrgicos de grandes animais. Contudo, trata-se de técnica invasiva e, portanto, não deixando de apresentar riscos, embora as suas vantagens excedam as desvantagens. Neste aspecto, além de possibilitar a administração de anestésicos inalatórios durante o ato operatório, assegura via prévia à passagem de ar enquanto o paciente está inconsciente; prevenindo aspiração de secreçōes; reduzindo o espaço morto das vias aéreas superiores e permitindo ventilação mais eficaz; facilitando a administração de oxigênio e até permitindo o controle da ventilação pulmonar em toracotomias, entre outras vantagens (Hall: Clarke', 1983).

De outra parte. ao lado das vantagens referidas, podem ocorrer alguns aspectos indesejáveis com a intubação endotraqueal, tais como: a contaminação bacteriana do trato respiratónio, hemorragias e lesões por compressão da mucosa da traquéia decorrentes de alta pressão aplicada no balão da sonda endotraqueal (Auler Jr. et al.', 1992). O objetivo desse trabalho foi procurar indícios de que a sonda endotraqueal pode provocar lesões nas vias aéreas superiores dos eqüinos quando submetidos à intubação endotraqueal e quais suas possíveis consequiências.

\section{LITERATURA}

No concemente à literatura sobre o aludido assunto. observa-se que poucas são as informações fornecidas sobre os eqüinos, tendo sido a maioria dos trabalhos realizados na espécie humana.

Em pequenos animais, a estenose traqueal é seqüela típica de trauma neste orgão, traqueostomia, ressecções traxueais ou motivadas por lesão isquêmica provocada pelo balão do tubo endotraqueal (Tangner, Hedlund ${ }^{18}, 1983$ ). Assim, as lesões podem variar desde edema e ulceração superficial até o desenvolvimento de necrose isquêmica com tecido de granulação, o qual é substituído por tocido fibroso, redundando em estreitamento do lúmen traqueal (Bojrab; Renegar', 1981). Os animais com tal quadro podem ter em seu históricooempregode anestesia inalatónia (Hedlund ${ }^{10}$, 1987).

Em cães, Bojrab; Renegar' (1981) afirmam que o balão do tubo endotraqueal infladoé o causador da isquemia por compressão da mucoß̀a traqueal. Recomendam então, que, para reduzir a possibilidade de aparecimento de estenose traqueal, deve-se atentar para o grau de pressão imprimida e o tempo em que o balão ficará inflado pressionando a parede cha traquéia.

Knecht et al. ${ }^{13}$ (1972); Klainer et al. ${ }^{12}$ (1975) e Sutter et $a l .{ }^{17}(1972)$ encontraram lesões traqueais em animais que sofreram intubação endotraqueal por procedimentos cirírgicos, tais como estenoses, modifi- 
contram-se no Quadro 2.

5. Após 24 horas do segundo exame endoscópico. conforme se deprezande do Quadro 3, as lesĩes mostravan-se presentes em todos os animais. sendo que naqueles que apresentavam escoriação, ulceração e hemalomas no segundo exame, ainda se denotavam as referidas lesões. passiadias 24 horas.

6. Não foran observadas diferenças que pudessem correlacionar aparecimento de lesĩo e es parâmetros analisidos segundo metodologia aplicadia.

7. Assim pudemos observar (Quadro 2) equimose (independente do grau) nas conchas nasais em 4 vezes ( $10 \%$ ). na epiglote em 14 oportunidades (35\%), na aritenóide em 30 vezes (75\%), nas cordas vocais em 36 ocasiōes ( $90 \%$ ). na traquéia em 27 vezes $(67.5 \%$ ) e na região do
"Cuff" em 39 vezes $(97,5 \%)$ no exame realizado após a recuperação da anestesia. Da mesma forma. hematomas foram observados em duas (xasiöes $(6,66 \%)$, sendo as duas vezes em traquéia. Já ulceração foi obșervada uma única vez $(3,33 \%)$ na traquéia. enquanto que excoriações (feridias) puderam ser constatadas em cinco oportunidades (12,5\%) - sendo todas vistas em epiglote.

8. Ao verificarmos pelo exame endoscópico, realizado 24 horas (conforme Quadro 3) após a segunda endoscopia, constatamos o que segue. Equimose (independente do grau) - conchas nasais - 4 vezes (10\%). epiglote - 6 vezes ( $15 \%$ ). aritnóide - 10 vezes ( $25 \%$ ), cordas vocais - 28 vezes $(70 \%)$, traquéia - 17 vezes $(42.5 \%)$, região do "Cuff" - 37 vezes $(92.5 \%)$, hematomas - 2 vezes $(6,66 \%)$ na traquéia. ulceração - 1 véz $(3,33 \%)$ na traquéia e escoriação (foridas) - 4 vezes ( $10 \%$ ) na epiglote.

QUADRO 1

Dados dos eqülinos submetidos a intubaçăo endotraqueal relativos a tempo do ato operatório, ldade, raça, peso, sexo, $n^{\circ}$ de tentativas, tamanho da sonda e pressāo do "Cuff". São Paulo, 1994.

\begin{tabular}{|c|c|c|c|c|c|c|c|c|}
\hline$N^{\circ}$ Animal & A & $\mathrm{B}$ & C & $\mathrm{D}$ & $E$ & $\mathrm{~F}$ & $\mathrm{G}$ & $H$ \\
\hline 1 & 180 & 42 & S.R.D. & 304 & Macho & 2 & 18 & 75 \\
\hline 2 & 180 & 264 & P.S.I. & 450 & Fêmea & 1 & 20 & 90 \\
\hline 3 & 100 & 36 & $1 / 2$ árabe & 360 & Macho & 2 & 30 & 100 \\
\hline 4 & 70 & 7 & S.R.D. & 145 & Fêmea & 1 & 18 & 180 \\
\hline 5 & 30 & 96 & Mangalarga & 450 & Macho & 1 & 26 & 90 \\
\hline 6 & 80 & 60 & S.R.D. & 350 & Macho & 1 & 26 & 40 \\
\hline 7 & 60 & 132 & S.R.D. & 480 & Macho & 1 & 30 & 50 \\
\hline 8 & 220 & 48 & S.A.D. & 320 & Fêmea & 1 & 18 & 70 \\
\hline 9 & 120 & 54 & S.R.D. & 300 & Fêmea & 1 & 18 & 70 \\
\hline 10 & 90 & 108 & Mangalarga & 460 & Macho & 1 & 18 & 55 \\
\hline 11 & 110 & 60 & S.R.D. & 450 & Macho & 1 & 26 & 60 \\
\hline 12 & 90 & 60 & S.R.D. & 300 & Macho & 1 & 18 & 60 \\
\hline 13 & 120 & 60 & Mangalarga & 436 & Fêmea & 1 & 26 & 100 \\
\hline 14 & 30 & 60 & Mangalarga & 345 & Macho & 1 & 26 & 60 \\
\hline 15 & 150 & 48 & Anglo Arabe & 436 & Macho & 1 & 26 & 50 \\
\hline 16 & 110 & 156 & S.R.D. & 370 & Macho & 2 & 26 & 130 \\
\hline 17 & 120 & 18 & P.S.A. & 300 & Fêmea & 1 & 18 & 85 \\
\hline 18 & 90 & 96 & A. Trotter & 325 & Macho & 1 & 26 & 115 \\
\hline 19 & 120 & 72 & 1/2 P.S.I. & 430 & Fêmea & 1 & 26 & 110 \\
\hline 20 & 30 & 60 & Manqalarga & 380 & Macho & 1 & 26 & 100 \\
\hline 21 & 120 & 204 & A. Trotter & 450 & Macho & 1 & 26 & 100 \\
\hline 22 & 120 & 72 & S.R.D. & 300 & Macho & 1 & 18 & 130 \\
\hline 23 & 45 & 54 & S.R.D. & 370 & Macho & 1 & 26 & $?$ \\
\hline 24 & 120 & 60 & S.R.D. & 370 & Macho & 1 & 26 & 125 \\
\hline 25 & 90 & 276 & 1/2 P.S.I. & 413 & Macho & 1 & 26 & 99 \\
\hline 26 & 150 & 216 & P.S.I. & 450 & Macho & 1 & 26 & 119 \\
\hline 27 & 60 & 72 & S.A.D. & 320 & Macho & 1 & 18 & 96 \\
\hline 28 & 120 & 288 & S.R.D. & 370 & Macho & 1 & 26 & 117 \\
\hline 29 & 180 & 48 & A. Arabe & 420 & Macho & 1 & 26 & 100 \\
\hline 30 & 120 & 216 & 1/2 P.S.I. & 410 & Macho & 1 & 26 & 80 \\
\hline 31 & 150 & 72 & A. Trotter & 400 & Macho & 1 & 26 & 150 \\
\hline 32 & 120 & 36 & P.S.A. & 272 & Fêmea & 1 & 18 & 140 \\
\hline 33 & 90 & 48 & A. Trotter & 367 & Macho & 1 & 26 & 130 \\
\hline 34 & 120 & 108 & B. Hipismo & 520 & Macho & 1 & 26 & 110 \\
\hline 35 & 150 & 18 & Mangalarga & 250 & Fêmea & 1 & 18 & 90 \\
\hline 36 & 120 & 30 & Mangalarga & 390 & Fêmea & 1 & 26 & 140 \\
\hline 37 & 60 & 96 & Criolo & 400 & Macho & 1 & 26 & 230 \\
\hline 38 & 75 & 84 & A. Trotter & 385 & Macho & 1 & 26 & 100 \\
\hline 39 & 180 & 288 & S.R.D. & 380 & Macho & 1 & 26 & 160 \\
\hline 40 & 240 & 312 & S.R.D. & 345 & Macho & 1 & 26 & 140 \\
\hline
\end{tabular}

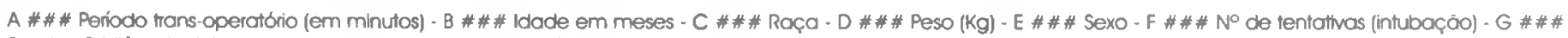
Sonda n (diámetro interno em mm) - H \# \# \# Pressão no "Cuff" (mm Hg) - ? \# \# \#ado não coletado 
FREITAS. R.R.; STOPIGLIA, A.J.; SILVA, L.C.L.C.; FANTON, D.T. Lesões das vias aéreas superiores após intubação endotraqueảl em eqüinos. Braz. J. vet. Res. anim?. Sci., Sāo Paulo, v.34, n.2, p.92-98, 1997

\section{QUADRO 3}

Lesōes observadas, segundo o tipo e o grau, em diferentes regiōes das vias aéreas superiores de eqüinos submetidos a intubação endotraqueal, 24 horas após a realizaçāo do segundo exame endoscópico. Sōo Paulo, 1994.

\begin{tabular}{|c|c|c|c|c|c|c|c|}
\hline № Animal & $\begin{array}{l}\text { Conchas } \\
\text { Nasais }\end{array}$ & Epiglote & Aritenóides & $\begin{array}{l}\text { Cordas } \\
\text { Vocais }\end{array}$ & $\begin{array}{l}\text { Terço Incial } \\
\text { da Traquéia }\end{array}$ & $\begin{array}{l}\text { Terço Médio } \\
\text { da Traquéia }\end{array}$ & $\begin{array}{l}\text { Posição do } \\
\text { "CUFF" }\end{array}$ \\
\hline 1 & & & Equimose (+) & & Equimose $(+)$ & & Equimose $(t+)$ \\
\hline 2 & Equimose (t) & Equimose (+) & Equimose (t) & & Equimose (+) & Ulceração (t) & Equimose $(++)$ \\
\hline 3 & & Equimose $(+)$ & Equimose (+) & & Equimose (t) & & Equimose $(++)$ \\
\hline 4 & & & & Equimose (+) & & & \\
\hline 5 & & & Equimose (+) & & & & Equimose (+) \\
\hline 6 & & & Equimose (t) & & & & \\
\hline 7 & & Equimose (t) & Equimose $(+)$ & Equimose (+) & Equimose $(++)$ & Hematoma (+) & Equimose $(++)$ \\
\hline 8 & & & & & & & Equimose (+) \\
\hline 9 & & & & & Equimose (+) & & Equimose (+) \\
\hline 10 & & & & & & & Equimose (t) \\
\hline 11 & & & Equimose (t) & Equimose $(+)$ & Equimose (+) & Hematoma (+) & Equimose $(++)$ \\
\hline 12 & & & & Equimose (+) & & & Equimose (+) \\
\hline 13 & & & & Equimose (+) & & & Equimose (t) \\
\hline 14 & & & & Equimose (+) & & & Equimose (t) \\
\hline 15 & & & & Equimose (+) & & & Equimose (+) \\
\hline 16 & & & & Equimose (+) & Equimose (+) & & Equimose $(++)$ \\
\hline 17 & & & & Equimose (+) & & & Equimose (+) \\
\hline 18 & & & & Equimose (+) & & & Equimose (+) \\
\hline 19 & & & & Equimose (+) & & & Equimose (t) \\
\hline 20 & & Escoriaçāo (t) & & Equimose (+) & & & Equimose (t) \\
\hline 21 & & & & Equimose $(+)$ & & & Equimose $(+)$ \\
\hline 22 & & & & Equimose (+) & & & Equimose (t) \\
\hline 23 & & Escoriação (++) & & Equimose (t) & & & \\
\hline 24 & & Equimose $(++)$ & & Equimose (+) & & & Equimose $(++)$ \\
\hline 25 & Equimose (+) & & & & & & Equimose $(++)$ \\
\hline 26 & Equimose (+) & & & & & & Equimose (+) \\
\hline 27 & & & Equimose (+) & Equimose (+) & Equimose $(++)$ & & Equimose (+) \\
\hline 28 & & & & Equimose (+) & & & Equimose (+) \\
\hline . 29 & & Equimose $(+)$ & & Equimose (++) & Equimose $(+++)$ & & Equimose $(+++)$ \\
\hline 30 & - & Equimose (+) & & & Equimose (+) & & Equimose $(++)$ \\
\hline 31 & Equimose (t) & & & & Equimose (+) & & Equimose (+) \\
\hline 32 & & & 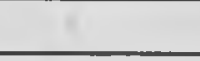 & Equimose $(+)$ & Equimose $(+)$ & & Equimose (+) \\
\hline 33 & & & Equimose (+) & Equimose (t) & Equimose (+) & Equimose $(t++)$ & Equimose $(++)$ \\
\hline 34 & & & & Equimose (+) & Equimose (t) & Equimose $(++)$ & Equimose $(++)$ \\
\hline 35 & & & & Equimose (+) & & & Equimose (+) \\
\hline 36 & & & & Equimose (+) & Equimose (t) & Equimose (+) & Equimose $(++)$ \\
\hline 37 & & $\begin{array}{c}\text { Equimose }(+) \\
\text { Escoriação }(+) \\
\end{array}$ & Equimose $(+)$ & Equimose $(++)$ & Equimose (+) & Equimose $(++)$ & Equimose $(++)$ \\
\hline 38 & & & & Equimose (+) & & & Equimose (+) \\
\hline 39 & & & & Equimose (+) & & & Equimose (+) \\
\hline 40 & & & & Equimose (+) & Equimose $(++)$ & Equimose $(++)$ & Equimose (++) \\
\hline
\end{tabular}




\section{DISCUSSÃO}

Conforme se depreende da literatura compulsada, observa-se que poucos foram os autores que se preocuparam em estudar os animais da espécie eqüina e as lesões motivadas pela intubação endotraqueal e suas conseguiências, cabendo a maioria dos artigos sobre o assunto em tela à espécie humana ou à canina.

Em todos os animais do experimento realizou-se exame endoscópico prévio à intubação endotraqueal, com a finalidade de descartar aqueles equiinos que porventura apresentassem lesões antes do procedimento cirúrgico. Nesse aspecto não foram utilizados no experimento quatro eqüinos que apresentavam esse tipo de problema, oriundo da passagem de sonda nasogástrica devido à síndrome cólica.

Observou-se que uma vez submetidos a indução anestésica. todos os animais permitiram a introdução da sonda através da laringe logo na primeira tentativa ou quando muito na segunda vez. Acredita-se que este momento seja responsável pelo aparecimento de lesões na epiglote, visto que movimentos abruptos, pouco delicados, com o intuito de introduzir a sonda à força, poderiam eventualmente provocar traumatismos. como escoriações ou hematomas. Ao analisarem-se os dados da tabela, não sc corrclacionou o número de tentativas para a intubação e a ocorrência de lesâo, à semelhança do observado por Heath et al. ${ }^{9}$ (1989).

No atinente àqueles animais com raça definida, meiosangue ou sem raça definida, constatou-se, da mesma forma, que este fator não foi determinante ao aparecimento ou não de lesões após a sondagem endotraqueal. Apuraramse lesões, principalmente as equimoses em seus diversos graus. em animais com ou sem raça defïnida. Neste aspecto. tampouco foram vistas diferenças preponderantes que pudessem significar que idade. sexo ou peso interferissem no aparecimento ou não de lesões.

Quanto ao tempo em que os animais permaneceram intubados. não foi possível fazer correlação direta entre este fator e o aparecimento de determinadas lesões, visto que, animais com 45 minutos de intubação já apresentaram lesão do tipo escoriação, à semelhança de animais que permaneceram anestesiados por 120 minutos; enquanto um animal com 180 minutos intubado só apresentou equimose.

Neste aspecto, Nordin't (1977) cita que, na espécie humana. pressões maiores que $50 \mathrm{~mm}$ de $\mathrm{Hg}$ por 15 minutos destroem o epitélio, deixando a membrana basal exposta. Ainda este autor cita danos cm traquéia do tipo isquêmico, quando a pressão do "Cuff" na parede deste orgão excede a pressão da perfusão capilar (20 a $30 \mathrm{~mm}$ de $\mathrm{Hg}$ ). Assim, para Bernhard $^{2}$ (1979), pressão de $18 \mathrm{~mm}$ de $\mathrm{Hg}$ já previnem a aspiração de material líquido. Embora não fossem realizados exames histológicos da região da traquéia que mantinha o "Cuff", acredita-se que os dados levantados pelos autores citados, para o homem, não possam ser transportados diretamente para a Medicina veterinária, e mais especificamente para a espécie equiina.

Constataram-se, entre as lesões encontradas nos animais do nosso experimento, equimoses, ulcerações, hematomas e escoriações, mas jamais observaram-se perfurações faringeanas como relatou Brock $^{5}$ (1985) e nem hematomas em epiglote e aritenóide, como constatou Trim ${ }^{20}$ (1984), embora tivesse sido achado por nós este tipo de lesão em traquéia e pelo referido autor valendo-se de sonda sem "Cuff". Da mesma forma, no material do experimento, não se verificou retroversão de epiglote em nenhum dos quarenta casos observados, como referiram em três casos Dodman et al. ${ }^{6}(1986)$.

Heath et al." (1989) observaram em seus animais sempre lesão. incluindo muco traqueal abundante, equimose. hemorragia e placas diftéricas. Da mesma forma, verificaram-se lesões nos quarenta eqüinos analisados. Assim. estes autores encontraram nos eqüinos submetidos a intubação endotraqueal, cujas sondas possuíam "Cuff". lesão na traquéia em $95 \%$ dos casos e lesão na laringe em $85 \%$. Os dados encontrados por nós foram respectivamente de $97.5 \%$ e $100 \%$. Deste modo estes resultados foram bem próximos aos de Health et al. " (1989), quando comparados os dados de lesão na traquéia, e superiores quando comparados com os de lesão na laringe. As tentativas de intubação por parte dos citados autores tiveram média de 2.2 e o tempo do ato operatório de 149 minutos. Já no presente experimento, obteve-se a média de 1,075 tentativas e 113,25 minutos respectivamente. Assim, neste experimento, a média de tentativas para se intubar os eqüinos foi menor quando comparado ao valor expresso pelos aludidos autores.

A região de grande área eritematosa que envolvia completamente a circunferência da traquéia, observada pelos mesmos autores mencionados, foi encontrada no terço médio desta, o que corresponde à posição do "Cuff". Heath ef $a l{ }^{9}$ (1989) encontraram essa regiāo a aproximadamente 90 centímetros da extremidade das narinas, enquanto nós, a aproximadamente 80 centímetros.

Não foi possível executar a pesquisa em alguns animais pelo fato de esses não permanecerem 24 horas após a intervenção cirúrgica no Hospital Veterinário, o que inviabilizava o último exame endoscópico. Desta forma. esses animais foram excluídos do experimento.

\section{CONCLUSÕES}

Pelos resultados obtidos com a metodologia empregada, concluiu-se que:

1. Intubações endotraqueais em eqüinos podem provocar lesões nas vias aéreas superiores.

2. Entre as lesões observadas constatamos: equimose, ulceração, hematomas e escoriação.

3. O local com lesões observado com maior frequência foi a região da traquéia onde se posiciona o "Cuff".

4. A lesão encontrada com maior frequência foi a equimose. 


\section{SUMMARY}

Nowadays, endotracheal intubation in equines is a normal routine in surgery rooms of great Universities, Jockey Clubs, and so forth. It is an invasive procedure, so it presents risks, although its advantages exceed a lot its disadvantages. The will of this experiment was to look for indicating that the endotracheal azode could cause lesions in the equine upper airways tract, as well as its possible consequences. The results were evaluated by the time spend in the surgery, age of equines, the animals breed, weight, sex, number of attempts necessary to intubate, tubes diameter and Cuff's pressure. The lesions were evaluated by their type and grade there were. No lesion, Light lesion, where there were ecchymoses wich were classified by the intensity of the lesions in $(+),(++),(+++)$. Moderate lesions, where we observed hematomas, that by their grade were $(+),(++),(++t)$. Severe lesions, where we catalogued ulcer, which by their grade were shared in $(+),(++),(+++)$. Lesions like lacerations which were classified in light, moderate and severe; and which, by the grade of lesions correspond to light, $(++)$ moderate and $(+++)$ severe. We also had perforations. Evaluating these results, we observed no differences correlating the appearance of the lesion with tract, as well as its possible consequences the evaluated parameters performed by the applied methodology.

Overall results showed that endotracheal intubations in equines caused lesions in the upper airways tract; the lesions found were: ecchymoses, hematomas, ulcerations and lacerations; the most frequent lesion site was Cuff's place in the trachea; the most frequent lesion was the ecchymosis.

UNITERMS: Endotracheal intubation; Lesions; Equidae

\section{REFERENCIAS BIBLIOGRÁFICAS}

I-AULER JR., J.O.C.; FELTRIM, M.I.Z.; FERREIRA, C.A.S.; OLIVEIRA, C Avaliação da pressão do balão do tubo endotraqueal nas primeiras horas do pós-operatório imediato de cirurgia cardíaca. Revista Brasileira de Terapia Intensiva v.4, n.4, p.116-9, 1992.

2-BEECH, J. Equine respiratory disorders. Philadelphia, Lea \& Febiger, 1991. $458 \mathrm{p}$.

3-BERNHARD, W.N.; COTTRELL. J.E.; SIVAKUMARAN, C.; PATEL, K. YOST, L.; TURNDORF, H. Adjustment of intracuff pressure to prevent aspiration. Anesthesiology, v.50, n.7, p.363-6, 1979.

4-BOJRAB, M.J.; RENEGAR, W.R. The trachea. In: BOJRAB, M.J. ed. Pathophisiology in small animal surgery, Philadelphia. Lea \& Febiger. 1981. p.359-68.

5-BROCK. K.A. Pharingeal trauma from endotracheal intubation in a colt Journal of American Veterinary Association. v.187, n.9, p.944-6. 1985.

6-DODMAN, N.H.; KOBLIK, P.D.; COURT, M.H. Retroversion of the epiglottis as a complication of endotracheal intubation in the horse. Veterinary Surgery, v.15, n.3, p.275-8, 1986.

7-HALL, L.W.; CLARKE, K.W. Veterinary Anaesthesia, 8. ed., London, Bailliere Tindall, 1983,417p.

8-HARDY, J.; STEWART, R.H.; BEARD, W.L. Complication of nasogastric intubation in horses: nine cases (1987-1989). Journal of the American Veterinary Medical Association. v.201, n.3, p.483. 1992.

9-HEATH, R.B.; STEFFEY, E.P.; THURNOM, J.C. Laringotracheal lesions following routine orotracheal intubation in the horse. Equine Veterinary Journal. v.21, n.6. p.434-7, 1989.

10-HEDLUND, C.S. Surgical diseases of the trachea. Veterinary Clinics of North America Small Animal Practice, v.17, n.2, p.301-32, 1987.

11-HOLLAND. M.; SNYDER, J.R.; STEFFEY, E.P. ; HEATH, R.B. Laryngotracheal injury associated with nasotracheal intubation in the horse. Journal of the American Veterinary Medical Association, v. 189, n.11, p.1447-50, 1986.

12-KLAINER, A S.; URNDORF, H; AKWAL, H; ALLANDER, P. Surface Alterations due to endotracheal intubation. American Journal of Medicine, v.208, n.58, p.674-83. 1975.

13-KNECHT, C.D.; SCHALL, W.D.: BARRET, R. Iatrogenic tracheostenosis in a dog. Journal of the American Veterinary Association. v.160, n. 10 , p.1427-9, 1972.

14-LUMB, W.V.; JONES, E.W. Veterinary anesthesia, 2. ed. Philadelphia, Lea \& Febiger, 1984. 69.3p.

15-MUIR. W.W.: HUBBELL. J.A.E. Equine anesthesia. St. Louis, Mosby. 199] $515 p$.
16-NORDIN, U. The trachea and cuff - induced tracheal injury. Acta Otolaryngology, Stock. v.7. p.7-69. 1977. Suppl. 345.

17-SUTTER, P.F.; COLGROVE, D.J.; EWING, G.O. Congenital hipoplasia of the canine trachea. The Journal of the American Animal Hospital Association. v.74, n.8. p. 120, 1972.

18-TANGNER, C.H.; HEDLUND, C.S. Tracheal surgery in the dog - Part I. Compendium on Continuing Education for the Practicing Veterinarian. v.5, n. 8, p.599-606, 1983.

19-TRAUB-DARGATZ, J.L.; BROWN, C.M. Equine Endoscopy, St. Louis. Mosby, 1990. p.75-84.

20-TRIM. C. M. Complications associated with the use of the cuffless endotraqueal tube in the horse. Journal of the American Veterinary Medical Association. v.185, n.5, p.541-2, 1984.

21-WEBB, A.I. Nasal Intubation in the foal. Journal of the American Veterinary Medical Association. v.185, n.1, p.45-51, 1984.
Recebido para publicação: 22/09/95 Aprovado para publicação: 24/06/96 